\title{
Multidrug Resistance in Hepatocellular Carcinoma
}

\author{
Baojun Duan ${ }^{1} \bullet$ Chen Huang$^{2} \bullet \mathrm{Jun} \mathrm{Bai}^{1} \bullet \mathrm{Yu}_{\text {Lian Zhang }}^{3} \bullet$ \\ Xi Wang ${ }^{1} \bullet$ Juan Yang ${ }^{2} \bullet$ Jun $\mathrm{Li}^{4}$ \\ ${ }^{1}$ Department of Medical Oncology, Shaanxi Provincial People's Hospital, China; \\ ${ }^{2}$ Department of Cell Biology and Genetics, School of Basic Medical Sciences, Xi'an Jiaotong \\ University, China; ${ }^{3}$ Department of Neurology, Shaanxi Provincial People's Hospital, China; \\ ${ }^{4}$ Department of National \& Local Joint Engineering Research Center of Biodiagnostics and \\ Biotherapy, the Second Affiliated Hospital, Xi'an Jiaotong University, China
}

Author for correspondence: Baojun Duan, Department of Medical Oncology, Shaanxi provincial people's hospital, China. Email: duanbaojun.cn@163.com

Doi: http://dx.doi.org/10.15586/hepatocellularcarcinoma.2019.ch8

\begin{abstract}
Although there has been tremendous progress in the treatment of hepatocellular carcinoma over the past decades, multidrug resistance to chemotherapy and targeted therapy remains a major hindrance in its successful management. Multidrug resistance, whether intrinsic or extrinsic, is a multifactorial process that includes enhanced drug efflux, decreased drug uptake, intracellular sequestration, metabolic alterations, aberrant apoptotic and autophagic signaling, changes in tumor microenvironment, and acquisition of stem cell-like properties by the cancer cells. Although many experimental strategies have been developed to overcome drug resistance, translation of the knowledge to the clinic has not been crowned with success. This chapter provides an overview of the role of multidrug resistance in hepatocellular carcinoma and the potential approaches to overcome this obstacle.
\end{abstract}

Keywords: ATP-binding cassette transporter; drug efflux; drug sequestration; multidrug resistance; RNAi therapy

In: Hepatocellular Carcinoma. Janina E.E. Tirnitz-Parker (Editor), Codon Publications, Brisbane, Australia. ISBN: 978-0-9944381-8-8. 2019; Doi: http://dx.doi.org/10.15586/ hepatocellularcarcinoma.2019

Copyright: The Authors.

License: This open access article is licensed under Creative Commons Attribution 4.0 International (CC BY 4.0). https://creativecommons.org/licenses/by-nc/4.0/ 


\section{INTRODUCTION}

Hepatocellular carcinoma (HCC), the most common type of liver cancer, is increasing in prevalence with a high mortality rate. It is considered the fifth most detected cancer in men and seventh in women in the USA, and represents the third most leading cause of cancer-related death in the world. The highest incidence rate of liver cancer in the world occurs in Asia and Africa; hepatitis viruses (B and C) account for approximately $80 \%$ of all HCC cases (1). About $80 \%$ of HCC patients are currently diagnosed at advanced stages of the disease and are not suitable candidates for surgical resection of the tumor. Systemic chemotherapy with cytotoxic agents (5-Fluoracil, doxorubicin, cisplatin, and oxaliplatin) and targeted therapy with the tyrosine kinase inhibitor sorafenib are the main approaches for these patients; however, chemotherapy resistance remains a major clinical obstacle (2). In addition to drug resistance, sorafenib failed to be an optimal treatment modality for some advanced HCC patients due to adverse effects and high costs (1). Extensive studies have been carried out in the last few decades to enhance the efficacy of anticancer drugs by overcoming chemoresistance, but translating this knowledge to the clinic still represents a critical challenge. Thus, there is an urgent need to focus on elucidating the mechanisms of chemoresistance, especially multidrug resistance (MDR), and develop novel methods or tools for the treatment of HCC patients.

\section{MECHANISMS OF MDR}

MDR can be either intrinsic or acquired. In intrinsic resistance, the cancer cells are inherently resistant or unresponsive to therapeutics. In acquired resistance, cancer cells that were initially responsive become unresponsive during the course of treatment. MDR is multifactorial, and pleiotropic cellular signals are simultaneously involved in this process. These include upregulation of drug efflux, downregulation of drug uptake, sequestration of drugs, alteration in drugs metabolism, abnormal expression of non-coding RNAs, blockage of apoptotic signals, change of tumor environment, acquiring stem-cell like characteristics and autophagy (Figure 1) (3). More than one MDR mechanism can occur in a single cancer type, which pose significant challenges for a thorough understanding of the signaling network (4).

\section{Enhanced drug efflux}

Molecular pumps that transport cytotoxic drugs across the membrane of cancer cells represent a primary cause of chemotherapeutic resistance. Hyperactivation of these molecular pumps decreases intracellular drug concentrations and results in drug resistance. Permeability-glycoprotein, also referred to as P-gp, MDR-1, or ATP-binding cassette subfamily B member 1 (ABCB-1), is a well-studied $170 \mathrm{kDa}$ plasma membrane drug efflux protein. It belongs to the adenosine triphosphate binding cassette (ABC) transporter superfamily, which includes MRP-1 (MDR protein), TAP1 (Transporter 1, ATP-binding cassette subfamily B member), and 


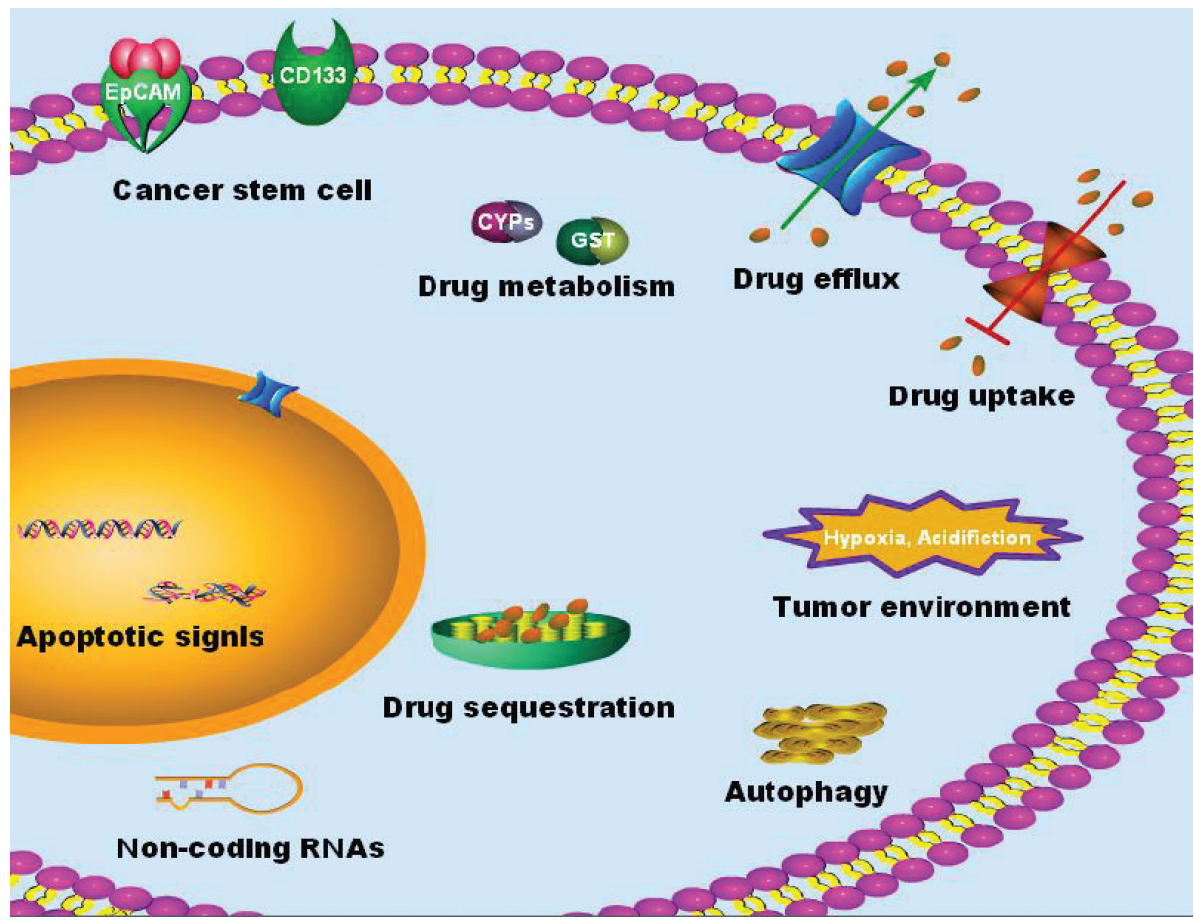

Figure 1 Multiple mechanisms of MDR in HCC. Multidrug resistance is a multifactorial process. Some of these include enhanced drug efflux, reduced drug intake, alterations in tumor microenvironment, impaired autophagy and apoptotic signals, lysosomal sequestrations, non-coding RNAs, alterations in drug metabolism, and acquisition of cancer stem cell-like phenotypes. CYPs, cytochrome P450 enzymes; GST, glutathione-S-transferase.

BCRP (breast cancer resistance protein) (5). ABC transporters are members of a conserved family of transmembrane proteins that utilize ATP as energy source to transport various substances, such as metabolic products, sterols, lipids, and drugs, across cellular membranes. The ABC proteins are comprised of cytosolic and transmembrane domains (6), and are essential for normal cellular functions. However, overexpression of ABC proteins in cancer cells usually leads to insufficient intracellular concentration and bioavailability of cytotoxic drugs as well as their metabolites (7). From a pharmacological point of view, although drug molecule-ABC interactions are very specific, one drug moiety can be a substrate of several ABC pumps (8). ABC proteins play a major role in the MDR of HCC $(9,10)$. The drug-resistant HCC cell line Bel7402/5-FU, developed by exposure to increasing concentrations of 5-FU, displays a higher expression of P-gp when compared with the parental cell line Bel7402. These cells are resistant not only to 5-FU but also to epirubicin (11). Kong et al. showed that P-gp and BCRP were highly expressed in the MDR HCC cells HepG2, which was induced by TGF- $\beta 1$ via the SMAD4/HOTAIR/MiR-145 axis. As a result, the concentration of imatinib in HepG2 cells was significantly decreased (12). Compared with parental cells, P-gp is significantly overexpressed in the sorafenib-resistant HCC cells, HepG2 
and Huh7. This was partially due to epithelial-mesenchymal transition (EMT) and AKT activation. Treatment with the novel allosteric AKT inhibitor MK-2206 reversed P-gp-mediated MDR via downregulation of phosphorylated AKT (13).

\section{Reduced drug uptake}

Drugs are transported across the cells by several mechanisms including passive diffusion and facilitated transport. The plasma membrane is an important barrier that limits drugs from reaching intracellular compartments. Passive transporters, ion-coupled transporters, and exchangers are encoded by genes of the solute carrier (SLC) family, which comprises approximately 360 uptake transporters in the cell membrane. Factors that downregulate or block the transporters can lead to drug resistance through decreased drug uptake or defective endocytic processes (14). Compared with non-tumor adjacent tissues, SLC46A3 was downregulated in $83.2 \%$ of human HCC tissues, and low expression was associated with a more aggressive phenotype. Conversely, overexpression of SLC46A3 was demonstrated to ameliorate sorafenib resistance, thereby improving the drug response, both in vitro and in vivo (15). SLCO1B3 is involved in the uptake of a number of chemotherapeutic agents, and its expression is significantly elevated in HCC patients with intratumoral cholestasis $(16,17)$. As a direct target of miRNA122, SLC7A1 is upregulated in miR122-silenced HCC cells, which is related to sorafenib resistance. Overexpression of miR122 can suppress SLC7Al levels and render HCC cells more sensitive to sorafenib (18). Gao et al. analyzed SLC family genes using qPCR array and identified 11 downregulated and 3 upregulated genes in HCC specimens, compared with the para-carcinoma tissues from HCC patients who underwent surgery. In addition, they found that SLC29Al was the only gene that correlated with poor prognosis and that it was significantly elevated in human HCC cell lines and tissues. Knockdown of SLC29Al decreased the sensitivity of HCC cells to 5-FU, cisplatin, and sorafenib in vitro (19).

\section{Drug sequestration}

Sequestration of drugs in cellular compartments is an important mechanism of chemotherapy resistance. Since drugs used in chemotherapy generally target molecules in the nucleus and other subcellular compartments, they must be able to achieve sufficient concentrations in these compartments and their microenvironments (20). Intracellular conditions such as intralumenal $\mathrm{pH}$, electrochemical potential, lipid compositions, and resident proteins can influence the intracellular localization of drugs. Multiple drug sequestration mechanisms may be involved in a single MDR cancer cell line, and the phenomena of drug sequestration may be more complex than originally thought (21). MDR cell lines show an increased capacity to sequester drugs into cytoplasmic compartments, resulting in decreased interactions of the drug with its nuclear targets. Colombo et al. (22) demonstrated P-gp expression not only on the cell membrane but also on lysosomes of six HCC cell lines and reported that cell lines with giant lysosomes were more resistant to sorafenib than those with small lysosomes. They concluded that lysosome-associated drug sequestration plays an important role in MDR in HCC cells (22). Metallothionein also plays a role in sequestering drugs 
within a cell. Sorafenib remarkably induces the expression of metallothionein$1 G$, which is a critical factor for sorafenib resistance in HCC. Inhibition of metallothionein-1G enhances the anticancer activity of sorafenib in vitro and in tumor xenograft models (23).

\section{Cellular metabolism}

The response to cytotoxic drugs often depends on the metabolic state of the cancer cells, and these cells rewire the metabolism of anticancer drugs. Metabolic alterations can be influenced by various factors such as oncogenes or tumor suppressor genes and the tumor microenvironment (24-29). Cancer cells that are resistant to cisplatin have high levels of reactive oxygen species (30), glutathione (GSH), and glutamate-cysteine ligase catalytic subunit (GCLC) $(31,32$ ). Downstream of survival signaling pathways, the Warburg effect, which refers to the increased rate of glycolysis in tumorigenic cells, can be observed even in conditions of normal oxygen levels. In c-Myc-driven HCC, glucose catabolism through glycolysis is elevated via the activation of pyruvate kinase (33). Inhibition of glycolysis and increase in oxidative phosphorylation can re-sensitize HCC cells to chemotherapeutics such as sorafenib, cisplatin, and isoliensinine (34). HIFl $\alpha$ activates the transcription of genes encoding angiogenic cytokines, for example, VEGF, and glycolytic enzymes, such as hexokinase 1, hexokinase 2, glyceraldehyde-3-phosphate dehydrogenase, and pyruvate kinase. These enzymes rewire the metabolism of cancer cells and induce MDR in HCC (35-38). Wu et al. showed that ADRB2 pathway regulation leads to HIFl $\alpha$ stabilization, reprogramming of glucose metabolism, and resistance of HCC cells to sorafenib (39). Drug metabolism enzymes are also involved in the MDR. This process includes phase I and phase II enzymes. Phase I of oxidative metabolism is mediated mainly by cytochrome P450 enzymes (CYPs) and epoxide hydrolases. Phase II enzymes are involved in conjugation reactions, including glutathionylation, glucuronidation, and sulfation. These enzymes include glutathione-Stransferase (GST), UDP-glucuronosyltransferases (UGT), sulfotransferases, and arylamine N-acetyltansferases (NAT), which transform the reactive species into hydrophilic nontoxic metabolite conjugates. Therapeutic drugs are metabolized by CYPs and epoxide hydrolases, which are further conjugated by the phase II enzymes and then, in phase III, effluxed by transporters such as the members of the $A B C$ transporter family (14). Meena et al. reported that CYP450 and fatty acid synthase protein levels were elevated in multidrug-resistant HCC cells, and downregulation of these molecules by siRNAs or cerulenin resensitized the cells to paclitaxel (40). Further, ciplatin-resistant HCC cell lines have a higher expression of GST, which can protect cancer cells from being inhibited by anticancer drugs (41).

\section{Non-coding RNAs}

The term "non-coding RNAs" (ncRNAs) refers to RNAs that do not encode proteins. These include miRNAs, long ncRNAs (lncRNAs), and circular RNAs (circRNA) (42). ncRNAs are involved in multiple cellular processes, such as proliferation, migration, apoptosis, angiogenesis, and immune responses (43). 
A number of studies have highlighted the key roles of ncRNAs in the evolution and progression of drug resistance in cancers. They mainly modulate drug transporters, cell cycle-related proteins, apoptotic signals, and the tumor microenvironment (44). While all ncRNAs potentially play roles in drug resistance in a context-specific manner, the major role is played by miRNAs and lncRNAs $(45,46)$. The miRNAs are small ( $20 \mathrm{bp})$ non-coding RNAs, which target specific mRNA sequences and inhibit protein translation (47).

One of the most abundantly expressed miRNA in the liver is miR-122, which plays a major role in basic liver function and homeostasis $(48,49)$. The loss of miR-122 is attributed to dysregulation of hepatocyte differentiation, poor prognosis, and metastasis of liver cancer. Restoration of miR-122 increased the sensitivity of drug-resistant HCC cells to cytotoxic agents through downregulation of MDRrelated genes, and inhibition of cell growth by cell cycle arrest at G0/G1 phase (50). Moreover, miRNA microarray data indicate that miR-122 is decreased in sorafenib-resistant HCC cells. miR-122 downregulation-mediated activation of insulin-like growth factor 1 and subsequent activation of the RAS/RAF/ERK pathway are thought to be the major mechanisms of resistance (51). He and colleagues found that miR-21 was overexpressed in sorafenib-resistant HCC cells, and inhibition of miR-21 with oligonucleotides resensitized these cells to sorafenib (52). They concluded that miR-21 participated in the acquired resistance of sorafenib by suppressing autophagy through the Akt/PTEN pathway (52). Multidrug-resistant Huh-7 cell lines, developed with increasing concentrations of doxorubicin, cisplatin, carboplatin, mitomycin C, and vincristine, demonstrated a significant differential profile of miRNAs when compared with the parental cell line. miR-27b, miR-18la, miR-146b-5p, miR-181d, and miR-146a were the most differentially expressed, and they are thought to play critical roles in the acquisition of MDR by regulating PTEN, P53, and KRAS (53).

\section{Apoptotic signals}

Apoptosis is involved in the regulation of many physiological and pathological processes (54). Disruption of apoptotic signals, one of the hallmarks of cancer, is a major obstacle in the success of chemotherapy. In general, there are two apoptotic pathways: (i) the intrinsic pathway involving the release of cytochrome c from mitochondria and (ii) the extrinsic pathway with the activation of death receptors. The initiation of these pathways results in the activation of caspases, which mediate the cleavage of cellular substrates, leading to morphological and biochemical changes that accompany apoptosis (55). DNA damage and oncogene activation either induce the accumulation of p53, which causes cell cycle arrest in the Gl phase, or trigger apoptosis, depending on the extent of DNA damage. Mutation or inactivation of p53 can result in chemotherapy resistance in cancer via suppression of apoptotic pathways (10). Zhang et al. reported that cisplatin reversed tumor necrosis factor (TNF)-related apoptosis-inducing ligand (TRAIL) resistance in HCC cells, dependent on the status of p53 (56). Modulating the expression of p53 and BCL-2 using long interspersed nuclear element-1 ORF-1 protein led to the resistance of HepG2 cells to cisplatin and epirubicin in vitro (57). The BCL-2 family, including pro-apoptotic proteins (BAX, BAK, BID, BAD, and PUMA) and anti-apoptotic proteins (BCL-2, BCL-xl, and MCL-1), can 
regulate apoptosis induced by wild-type p53 in response to stress. Mitochondrial pathway-associated chemotherapy resistance is mainly regulated by the BCL-2 family (14). BCL-2 plays a pivotal role in the glycochenodeoxycholate (GCDA)induced chemoresistance, while suppressing the GCDA-stimulated phosphorylation of BCL-2 significantly attenuates the survival and drug resistance in HCC cells (58). Sorafenib-resistant HCC cell lines, including HepG2R and Hep3BR, exhibit altered expression of BCL-2 and MCL-1. Navitoclax, an inhibitor of BCL-2, can restore the anticancer activity of sorafenib and regorafenib via a mitochondrial caspase-dependent mechanism in vitro and in vivo (59).

\section{Tumor microenvironment}

Solid tumors are heterogeneous structures. The tumor microenvironment is composed of cancer and stromal cells embedded in extracellular matrix, sustained by aberrant vasculature $(60,61)$. Tumor hypoperfusion, secondary to the hyperpermeability of the aberrant vasculature, along with low oxygen, depleted nutrition, low $\mathrm{pH}$, and high interstitial pressure can cause chemoresistance $(61,62)$. Compared to normal cells, cancer cells exhibit higher glucose metabolism rates and preferentially utilize glycolysis over oxidative phosphorylation, especially in hypoxic conditions (Warburg effect). This process ultimately generates lactic acid, leading to intracellular acidification $(63,64)$. As a result, cancer cells may express relatively more proton pumps in order to maintain intracellular $\mathrm{pH}$ homeostasis, rendering the extracellular environment highly acidic. According to the ion trapping theory, weakly basic drugs, such as doxorubicin, mitoxantrone, and vincristine, are ionized extracellularly and, as a consequence, lead to chemoresistance (14). Being an antiangiogenic agent, sorafenib treatment reduces tumor vessels, prompts hypoxia in the tumor microenvironment, and stimulates HIF-mediated cellular responses that favor the selection of chemo-resistant cells (65). Hypoxia has been shown to induce resistance to sorafenib, 5-FU, gemcitabine, cisplatin, adriamycin, and 6-thioguanine in BEL-7402, HepG2, and SMMC-7721 HCC cell lines (66).

\section{Cancer stem cells}

Cancer stem cells (CSCs) are a subpopulation of tumor cells with the capacity of self-renewal, differentiation, as well as drug resistance (14, 67, 68). CSCs in human HCC have been identified and validated through isolation and xenotransplantation experiments in animal models. These cells have pivotal roles in the development and progression of HCC (69) as well as chemotherapy resistance (66). CSC markers of HCC include epithelial cell adhesion molecule (EpCAM), CD133, CD90, CD44, CD24, CD13, deubiquitinating enzyme ubiquitin-specific protease 22 (USP22), and oval cell marker OV6. Some of these markers have been reported to confer chemoresistance to $\operatorname{HCC}(2,70,71)$. Multi-signal pathways and their cross-talk, including EpCAM, Wnt/ß-catenin, Sonic Hedgehog, and Notch, are required to maintain the stemness phenotype of HCC CSCs (67). $\mathrm{CD}_{133^{+}}$HCC cells isolated from human HCC cell lines and xenograft mouse models were resistant to chemotherapeutics, through the activation of Akt/PKB and Bcl-2 pathways (72). Downregulation of USP22 significantly suppressed the expression of $\mathrm{ABCCl}(\mathrm{MRP} 1)$ in an $\mathrm{HCC}$ cell line, with validation of the 
relationship between USP22 and ABCCl in clinical HCC tissue samples. These results suggest that USP22 is associated with the MDR phenotype of BEL-7402/ FU (71). In addition, GSK2879552 and pargyline, inhibitors of lysine-specific histone demethylase 1A (KDMlA or LSD1), were demonstrated to alleviate acquired resistance to sorafenib through the suppression of the $\mathrm{Wnt} / \beta$-catenin signaling pathway in HCC CSCs (73).

\section{Autophagy}

Autophagy is a highly conserved cellular "self-degradative" process, in which cytoplasmic components (long-lived or misfolded proteins, protein aggregates, and damaged organelles) are degraded and recycled to maintain homeostasis. Deficient autophagy is closely related to the development of many diseases including cancer. Autophagy occurs at a basal level in cells and can be induced by diverse signals and cellular stressors, including chemotherapeutic agents (74). In general, autophagy plays a dual role in the process of MDR in cancers. It not only contributes to the development of MDR, but also kills MDR cancer cells in which apoptosis pathways are inactive, leading to inconsistence results across studies $(75,76)$. Autophagy inhibitors can increase the sensitivity of HCC cells to cytotoxic agents (77). Fan et al. showed that elevated peptidylarginine deiminase IV (PADI4) was associated with chemoresistance through autophagy induction in HCC in vitro and in vivo. Inhibition of autophagy restored the sensitivity of HCC cells to chemotherapy (78). The exact relationship between autophagy and MDR in HCC remains unclear and requires further research.

\section{STRATEGIES TO OVERCOME MDR}

Extensive studies have been carried out during the last few decades to enhance the efficacy of chemotherapy by suppressing or evading the mechanisms of MDR. These approaches include the use of MDR modulators or chemosensitizers $(79,80)$, improved drug delivery $(81,82)$, RNAi therapy (83), and natural products (84).

\section{MDR modulators or chemosensitizers}

MDR modulators or chemosensitizers have been classified into first-generation, second-generation, and third-generation on the basis of their affinity for certain transporters and effects (5). As P-gp is the most extensively characterized transporter of the ABC superfamily, ways to modulate P-gp have been studied extensively. The first-generation P-gp modulators include verapamil, cyclosporine A, trifluoperazine, quinidine, progesterone, calmodulin antagonists, and tamoxifen. Kim et al. reported that a high dose of verapamil is required both clinically and experimentally to overcome MDR of HCC and that the combination of tamoxifen and cyclosporine A showed a significant reduction in the $\mathrm{IC}_{50}$ value of doxorubicin in MDR HCC cell lines (85). Due to disappointing therapeutic outcomes and high systemic toxicities, these modulators were replaced with the second-generation MDR modulators $(86,87)$ such as dexverapamil, valspodar, 
biricodar citrate, and dexniguldipine. Valspodar was shown to improve the anticancer effect of doxorubicin by modulating P-gp in HCC and hepatoblastoma cell lines (88). Although the second generation of MDR modulators can inhibit P-gp and increase the intracellular accumulation of drugs better than the first-generation modulators, there are several disadvantages that limit their clinical application. Numerous chemotherapeutics are substrates of both P-gp and cytochrome P450. Thus, the combination of anticancer agents with the second-generation MDR modulators may lead to unpredictable pharmacokinetic or incorrect dosing of chemotherapeutics $(5,89)$. The third-generation MDR modulators include tariquidar, zosuquidar, laniquidar, elacridar, mitotane, diarylimidazole, and annamycin. Comparative molecular field analysis (CoMFA) and comparative molecular similarity indices analysis (CoMSIA) associated with 3D-quantitiative structureactivity relationship (3D-QSAR) studies were performed to aid the research and design of the third-generation MDR modulators (90). These modulators are about 300 times more potent than the first- and second-generation modulators. Importantly, these agents do not interact with cytochrome P450 (90, 91). Takahata et al. found that breast cancer-resistant protein (BCRP) expression correlated well with the chemo-sensitivity of irinotecan hydrochloride (CPT-11) in HCC cell lines. Elacridar, an inhibitor of BCRP, enhanced the sensitivity of CPT-11 in BCRPoverexpressing KYN-2 cells (92).

\section{Enhanced drug delivery}

Nanotechnology has the power to deliver anticancer drugs and radically change chemoresistance of cancer cells by overcoming MDR (82). There are several drug delivery systems including liposomes, dendrimers, polymeric micelles, nanoparticles, polymer-drug/protein-conjugates, and carbon nanotubes. These nanoformulations may overcome several challenges in efficient drug delivery such as solubility, pharmacokinetic profiles, cellular uptake, bio-distribution patterns, circulation times, and clearance (93). For instance, pluronic P85 can sensitize MDR tumors to many chemotherapeutic agents through various mechanisms: (i) membrane fluidization, (ii) ATP depletion, (iii) direct interaction with the ABC efflux transporter, (iv) reduction of the GSH/GST detoxification system, (v) drug release from acidic vesicles, and (vi) incorporation into the mitochondrial membrane, thereby inhibiting cellular respiration (94). Moreover, all these nanomaterial-based drug delivery systems can be conjugated with various kinds of ligands (e.g., proteins, antibodies, and small molecules) producing the so-called actively-targeted material that favors drug targeting to specific cell surfaces and thus to specific cell populations, leading to a selective and reduced toxicity (82).

Polyethylene glycol (PEG) and polyethylenimine (PEI) co-conjugated ultrasmall nano-graphene oxide (NGO) loaded with C6-ceramide (NGO-PEG-PEI/ Cer) were reported to subvert MDR in HCC cells by inactivating MDR and AKT signaling. NGO-PEG-PEI/Cer combined with sorafenib represents a promising potential therapeutic strategy for the treatment of drug-resistant HCC (95). HA/ anti-miR-21/PPAuNCs, a nonviral gene delivery system, which condensed antimiR-21 into hyaluronic acid-conjugated and PEI-modified PEGylated gold nanocages (AuNCs), enhanced intracellular drug accumulation and restored sensitivity to doxorubicin in a doxorubicin-resistant HCC cell line through upregulating PTEN expression and downregulating P-gp (96). Bmil is essential for the survival 
and proliferation of liver CSCs. Yang et al. demonstrated that Bmil siRNA delivered via cationic nanocapsules of cisplatin (NPC/BmilsiR) eliminated the side population of CD133+ HCC cells dramatically and overcame drug resistance of HCC (97).

\section{RNAi therapy}

RNA interference (RNAi) is considered a highly specific approach for gene silencing and has emerged as a novel therapeutic tool for various pathologic conditions, including cancers $(98,99)$. RNAi molecules are a group of small regulatory RNAs that include miRNAs and small (or short) interfering RNAs (siRNAs). miRNAs are endogenous RNAs that are produced from non-coding RNAs, while siRNAs are derived from exogenous long dsRNAs (100, 101). In addition, exogenous short hairpin RNA precursors that are processed by a distinct cellular machinery to form siRNAs can also lead to effective gene silencing $(101,102)$. These artificially generated oligonucleotides mediate gene silencing through post-transcriptional mRNA cleavage and decomposition in the cytoplasm, resulting in the knockdown of target gene expressions $(98,103)$. Theoretically, RNAi-based strategies can be used in a wide variety of experimental models to target genes that are involved in disease processes $(103,104)$.

Enhancer of zeste homolog $2(\mathrm{EZH} 2)$ is overexpressed in the MDR HCC cell line Bel/Fu, and siRNA depletion of EZH2 sensitized these cells to 5-FU by inhibiting MDRl protein expression, promoting apoptosis, and inducing cell cycle arrest at G1/S phase (105). It has been reported that MAPK14/Atf2 signaling predicted a poor response to sorafenib in human HCC. Rudalska et al. demonstrated that silencing MAPK14 by shRNA reverted sorafenib resistance in HCC in vitro (106). Knockdown of the autophagy-related gene LC3 by RNAi significantly enhanced the sensitivity to epirubicin and inhibited proliferation of HepG2 cells (107). As silencing a single miRNA may sequentially activate other compensatory signaling pathways, a combinatorial approach modulating many miRNAs related to a signal pathway may be a promising strategy. The miRNAs miR-21, miR-153, miR-216a, miR-217, miR-494, and miR-10a-5p have been shown to be elevated in sorafenib-resistant HCC cells. Simultaneous targeting of these miRNAS using artificial long non-coding RNAs reversed sorafenib resistance in these cells both in vitro and in vivo (108). RNAi, apart from being a potential therapeutic tool, can also be used as a tool for biomarker screening for chemotherapy sensitivity. Through a high-throughput RNAi screening with 176 shRNA pools against 88 histone methyltransferases and histone demethyltransferases, Li et al. (109) found that silencing of the histone methyltransferases genes, ASH1L, C17ORF49, and SETD4, promoted the sensitivity of HepG2 cells to sorafenib.

\section{Natural products}

Natural products have attracted increasing attention as anticancer tools. A large pool of products with potential functions on reversing MDR have been identified and classified (Figure 2) (84, 110). Steroidal saponin from Trillium tschonoskii reversed MDR of HCC cell lines in a dose-dependent manner by inhibiting MDRrelated molecules such as MRP1, MRP2, MRP3, MRP5, MVP, and GST- $\pi$ (111). 


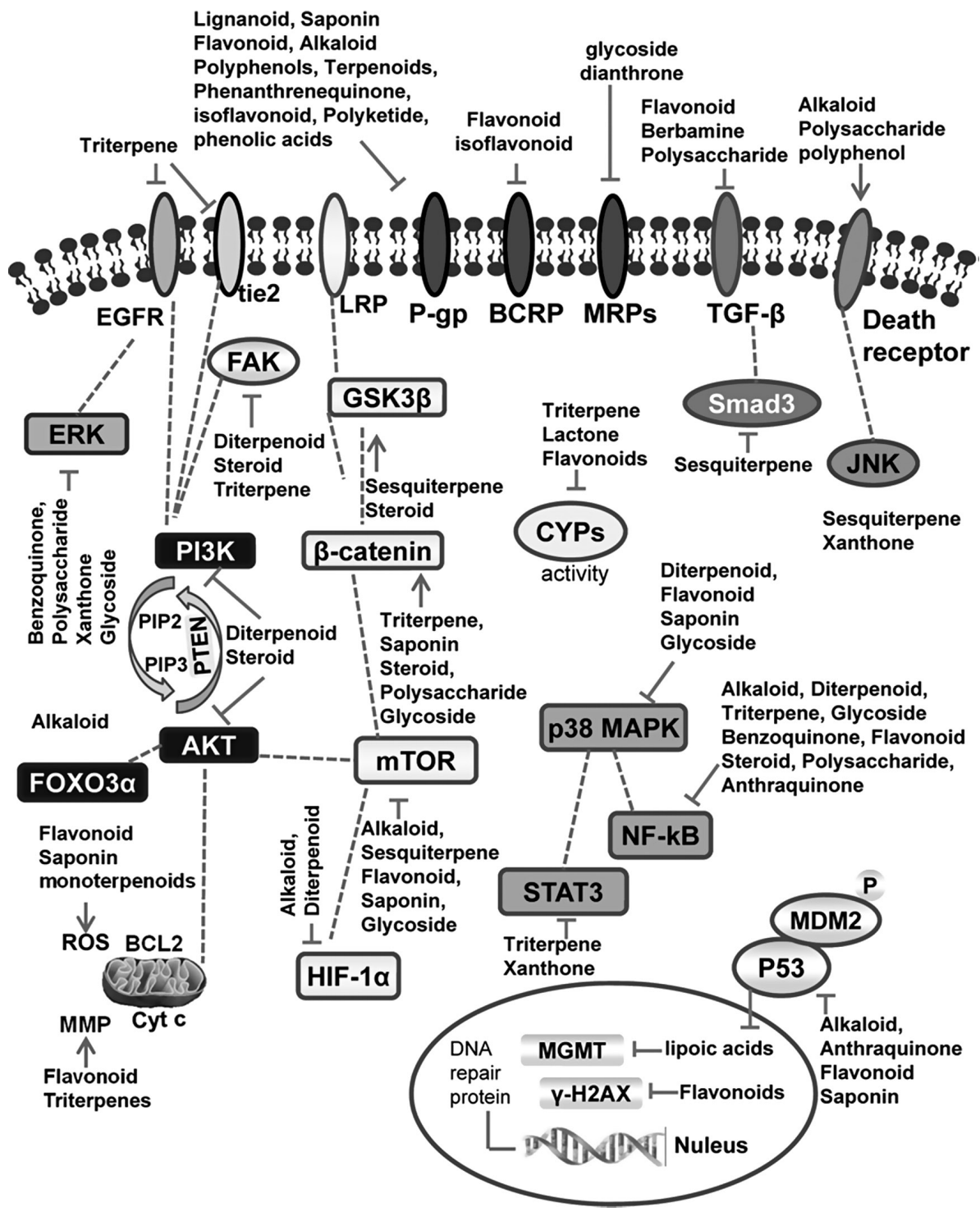

Figure 2 Natural products and their potential role in reversing MDR. Experimental data show that natural products can reverse MDR via regulating drug efflux, drug metabolism, and apoptotic pathways in cancer cells (110).

Treatment of HepG2/ADR cells with rhamnetin, derived from Persian berries, reduced the expression of Notch-1, P-gp, and BCRP and increased the susceptibility of HepG2/ADR cells to sorafenib, etoposide, and paclitaxel (112). Baicalein, isolated from Radix scutellariae, increased the intracellular accumulation of Rhol23 and epirubicin, induced apoptosis and autophagy, decreased the expression of P-gP and Bcl-xl, and reversed MDR in Bel7402/5-FU cells (11). 
Moreover, natural products can also increase the sensitivity of HCC cells to anticancer drugs by regulating cellular metabolism. Li and colleagues demonstrated that dauricine dose-dependently suppressed glucose glycolysis and increased oxidative phosphorylation by downregulating the expression of hexokinase 2 and pyruvate kinase M2, consequently increasing the sensitivities of HCC to cisplatin, sorafenib, and isoliensinie (34).

\section{CONCLUSION}

Despite a better understanding of the mechanisms of drug resistance, and the experimental approaches that have been taken to overcome drug resistance over the decades, clinical utility of these approaches has not come to fruition. To date, there is no effective tool to overcome MDR of HCC patients. Among the various strategies described to address drug resistance, nanotechnologies appear to offer particular advantages with their presumed target-specific delivery of chemotherapeutics and other conjugated agents. While RNAi can be designed for specific targets and used successfully in vitro, the in vivo silencing effects of RNAi are far from satisfactory even in highly controlled experimental conditions. Natural products can affect multiple targets and pathways with minimal side effects. However, the current literature is not sufficient to justify their use in clinical settings. Given that the liver plays a major role in drug metabolism and detoxification, and its function is already impaired in HCC patients, any drug combination that depends on normal liver metabolism is unlikely to be a successful strategy to overcome drug resistance. Taken together, continuous efforts are needed to explore the mechanisms in more detail and design novel approaches to overcome MDR to improve outcomes for HCC patients.

Conflict of Interest: The authors declare no potential conflicts of interest with respect to research, authorship, and/or publication of this article.

Copyright and Permission: To the best of our knowledge, the materials included in this chapter do not violate copyright laws. All original sources have been appropriately acknowledged and/or referenced. Where relevant, appropriate permissions have been obtained from the original copyright holder(s).

\section{REFERENCES}

1. Jindal A, Thadi A, Shailubhai K. Hepatocellular carcinoma: Etiology and current and future drugs. J Clin Exp Hepatol. 2019;9(2):221-32. http://dx.doi.org/10.1016/j.jceh.2019.01.004

2. Lohitesh K, Chowdhury R, Mukherjee S. Resistance a major hindrance to chemotherapy in hepatocellular carcinoma: An insight. Cancer Cell Int. 2018;18:44. http://dx.doi.org/10.1186/ s12935-018-0538-7

3. Filipits M. Mechanisms of cancer: Multidrug resistance. Drug Discov Today Dis Mech. 2004;2(1): 229-34. http://dx.doi.org/10.1016/j.ddmec.2004.10.001

4. Saraswathy M, Gong S. Different strategies to overcome multidrug resistance in cancer. Biotechnol Adv. 2013;31(8):1397-407. http://dx.doi.org/10.1016/j.biotechadv.2013.06.004 
5. Mohammad IS, He W, Yin L. Understanding of human ATP binding cassette superfamily and novel multidrug resistance modulators to overcome MDR. Biomed Pharmacother. 2018;100:335-48. http:// dx.doi.org/10.1016/j.biopha.2018.02.038

6. Velamakanni S, Wei SL, Janvilisri T, van Veen HW. ABCG transporters: Structure, substrate specificities and physiological roles: A brief overview. J Bioenerg Biomembr. 2007;39(5-6):465-71. http:// dx.doi.org/10.1007/s10863-007-9122-x

7. Ferreira RJ, Dos SD, Ferreira MJ. P-glycoprotein and membrane roles in multidrug resistance. Future Med Chem. 2015;7(7):929-46. http://dx.doi.org/10.4155/fmc.15.36

8. Fletcher JI, Haber M, Henderson MJ, Norris MD. ABC transporters in cancer: More than just drug efflux pumps. Nat Rev Cancer. 2010;10(2):147-56. http://dx.doi.org/10.1038/nrc2789

9. Ceballos MP, Rigalli JP, Cere LI, Semeniuk M, Catania VA, Ruiz ML. ABC transporters: Regulation and association with multidrug resistance in hepatocellular carcinoma and colorectal carcinoma. Curr Med Chem. 2019;26(7):1224-50. http://dx.doi.org/10.2174/0929867325666180105103637

10. Li S, Gao M, Li Z, Song L, Gao X, Han J, et al. p53 and P-glycoprotein influence chemoresistance in hepatocellular carcinoma. Front Biosci (Elite Ed). 2018;10:461-68. http://dx.doi.org/10.2741/e833

11. Li J, Duan B, Guo Y, Zhou R, Sun J, Bie B, et al. Baicalein sensitizes hepatocellular carcinoma cells to 5-FU and Epirubicin by activating apoptosis and ameliorating P-glycoprotein activity. Biomed Pharmacother. 2018;98:806-12. http://dx.doi.org/10.1016/j.biopha.2018.01.002

12. Kong J, Qiu Y, Li Y, Zhang H, Wang W. TGF-betal elevates P-gp and BCRP in hepatocellular carcinoma through HOTAIR/miR-145 axis. Biopharm Drug Dispos. 2019;40(2):70-80. http://dx.doi. org/10.1002/bdd.2172

13. Dong J, Zhai B, Sun W, Hu F, Cheng H, Xu J. Activation of phosphatidylinositol 3-kinase/AKT/ snail signaling pathway contributes to epithelial-mesenchymal transition-induced multi-drug resistance to sorafenib in hepatocellular carcinoma cells. PLoS One.2017;12(9):e185088. http://dx.doi. org/10.1371/journal.pone.0185088

14. Gillet JP, Gottesman MM. Mechanisms of multidrug resistance in cancer. Methods Mol Biol. 2010;596:47-76. http://dx.doi.org/10.1007/978-1-60761-416-6_4

15. Zhao Q, Zheng B, Meng S, Xu Y, Guo J, Chen LJ, et al. Increased expression of SLC46A3 to oppose the progression of hepatocellular carcinoma and its effect on sorafenib therapy. Biomed Pharmacother. 2019;114:108864. http://dx.doi.org/10.1016/j.biopha.2019.108864

16. Sekine S, Ogawa R, Ojima H, Kanai Y. Expression of SLCOlB3 is associated with intratumoral cholestasis and CTNNB1 mutations in hepatocellular carcinoma. Cancer Sci. 2011;102(9):1742-47. http://dx.doi.org/10.1111/j.1349-7006.2011.01990.x

17. de Morree ES, Bottcher R, van Soest RJ, Aghai A, de Ridder CM, Gibson AA, et al. Loss of SLCO1B3 drives taxane resistance in prostate cancer. Br J Cancer. 2016;115(6):674-81. http://dx.doi.org/ 10.1038/bjc.2016.251

18. Kishikawa T, Otsuka M, Tan PS, Ohno M, Sun X, Yoshikawa T, et al. Decreased miR122 in hepatocellular carcinoma leads to chemoresistance with increased arginine. Oncotarget. 2015;6(10):8339-52. http://dx.doi.org/10.18632/oncotarget.3234

19. Gao PT, Cheng JW, Gong ZJ, Hu B, Sun YF, Cao Y, et al. Low SLC29Al expression is associated with poor prognosis in patients with hepatocellular carcinoma. Am J Cancer Res. 2017;7(12):2465-77.

20. Kartal-Yandim M, Adan-Gokbulut A, Baran Y. Molecular mechanisms of drug resistance and its reversal in cancer. Crit Rev Biotechnol. 2016;36(4):716-26.

21. Duvvuri M, Krise JP. Intracellular drug sequestration events associated with the emergence of multidrug resistance: A mechanistic review. Front Biosci. 2005;10:1499-509. http://dx.doi.org/10.2741/1634

22. Colombo F, Trombetta E, Cetrangolo P, Maggioni M, Razini P, De Santis F, et al. Giant lysosomes as a chemotherapy resistance mechanism in hepatocellular carcinoma cells. PLoS One. 2014;9(12):el14787. http://dx.doi.org/10.1371/journal.pone.0114787

23. Sun X, Niu X, Chen R, He W, Chen D, Kang R, et al. Metallothionein- $1 G$ facilitates sorafenib resistance through inhibition of ferroptosis. Hepatology. 2016;64(2):488-500. http://dx.doi.org/10.1002/ hep. 28574

24. Cairns RA, Harris IS, Mak TW. Regulation of cancer cell metabolism. Nat Rev Cancer. 2011;11(2): 85-95. http://dx.doi.org/10.1038/nrc2981 
25. Stine ZE, Walton ZE, Altman BJ, Hsieh AL, Dang CV. MYC, Metabolism, and cancer. Cancer Discov. 2015;5(10):1024-39. http://dx.doi.org/10.1158/2159-8290.CD-15-0507

26. Kawada K, Toda K, Sakai Y. Targeting metabolic reprogramming in KRAS-driven cancers. Int J Clin Oncol. 2017;22(4):651-59. http://dx.doi.org/10.1007/s10147-017-1156-4

27. Liu CC, Chou KT, Hsu JW, Lin JH, Hsu TW, Yen DH, et al. High metabolic rate and stem cell characteristics of esophageal cancer stem-like cells depend on the Hsp27-AKT-HK2 pathway. Int J Cancer. 2019;145(8):2144-2156. http://dx.doi.org/10.1002/ijc.32301

28. Berkers CR, Maddocks OD, Cheung EC, Mor I, Vousden KH. Metabolic regulation by p53 family members. Cell Metab. 2013;18(5):617-33. http://dx.doi.org/10.1016/j.cmet.2013.06.019

29. Semenza GL. HIF-1: Upstream and downstream of cancer metabolism. Curr Opin Genet Dev. 2010;20(1):51-56. http://dx.doi.org/10.1016/j.gde.2009.10.009

30. Wangpaichitr M, Sullivan EJ, Theodoropoulos G, Wu C, You M, Feun LG, et al. The relationship of thioredoxin-1 and cisplatin resistance: Its impact on ROS and oxidative metabolism in lung cancer cells. Mol Cancer Ther. 2012;11(3):604-15. http://dx.doi.org/10.1158/1535-7163.MCT-11-0599

31. Catanzaro D, Gaude E, Orso G, Giordano C, Guzzo G, Rasola A, et al. Inhibition of glucose-6phosphate dehydrogenase sensitizes cisplatin-resistant cells to death. Oncotarget. 2015;6(30): 30102-14. http://dx.doi.org/10.18632/oncotarget.4945

32. Catanzaro D, Nicolosi S, Cocetta V, Salvalaio M, Pagetta A, Ragazzi E, et al. Cisplatin liposome and 6-amino nicotinamide combination to overcome drug resistance in ovarian cancer cells. Oncotarget. 2018;9(24):16847-60. http://dx.doi.org/10.18632/oncotarget.24708

33. Mendez-Lucas A, Li X, Hu J, Che L, Song X, Jia J, et al. Glucose catabolism in liver tumors induced by c-MYC can be sustained by various PKM1/PKM2 ratios and pyruvate kinase activities. Cancer Res. 2017;77(16):4355-64. http://dx.doi.org/10.1158/0008-5472.CAN-17-0498

34. Li W, Qiu Y, Hao J, Zhao C, Deng X, Shu G. Dauricine upregulates the chemosensitivity of hepatocellular carcinoma cells: Role of repressing glycolysis via miR-199a:HK2/PKM2 modulation. Food Chem Toxicol. 2018;121:156-65. http://dx.doi.org/10.1016/j.fct.2018.08.030

35. Hamaguchi T, Iizuka N, Tsunedomi R, Hamamoto Y, Miyamoto T, Iida M, et al. Glycolysis module activated by hypoxia-inducible factor lalpha is related to the aggressive phenotype of hepatocellular carcinoma. Int J Oncol. 2008;33(4):725-31.

36. Lau CK, Yang ZF, Ho DW, Ng MN, Yeoh GC, Poon RT, et al. An Akt/hypoxia-inducible factor-lalpha/ platelet-derived growth factor-BB autocrine loop mediates hypoxia-induced chemoresistance in liver cancer cells and tumorigenic hepatic progenitor cells. Clin Cancer Res. 2009;15(10):3462-71. http:// dx.doi.org/10.1158/1078-0432.CCR-08-2127

37. Daskalow K, Rohwer N, Raskopf E, Dupuy E, Kuhl A, Loddenkemper C, et al. Role of hypoxiainducible transcription factor lalpha for progression and chemosensitivity of murine hepatocellular carcinoma. J Mol Med (Berl). 2010;88(8):817-27. http://dx.doi.org/10.1007/s00109-010-0623-4

38. Lee M, Ko H, Yun M. Cancer metabolism as a mechanism of treatment resistance and potential therapeutic target in hepatocellular carcinoma. Yonsei Med J. 2018;59(10):1143-49. http://dx.doi. org/10.3349/ymj.2018.59.10.1143

39. Wu FQ, Fang T, Yu LX, Lv GS, Lv HW, Liang D, et al. ADRB2 signaling promotes HCC progression and sorafenib resistance by inhibiting autophagic degradation of HIFlalpha. J Hepatol. 2016;65(2): 314-24. http://dx.doi.org/10.1016/j.jhep.2016.04.019

40. Meena AS, Sharma A, Kumari R, Mohammad N, Singh SV, Bhat MK. Inherent and acquired resistance to paclitaxel in hepatocellular carcinoma: Molecular events involved. PLoS One. 2013;8(4):e61524. http://dx.doi.org/10.1371/journal.pone.0061524

41. Yang JX, Luo Y, Qiu HM, Tang WX. Characterization and resistance mechanisms of cisplatin-resistant human hepatocellular carcinoma cell line. Saudi Med J. 2009;30(1):35-40.

42. Birney E, Stamatoyannopoulos JA, Dutta A, Guigo R, Gingeras TR, Margulies EH, et al. Identification and analysis of functional elements in $1 \%$ of the human genome by the ENCODE pilot project. Nature. 2007;447(7146):799-816. http://dx.doi.org/10.1038/nature05874

43. Xie N, Liu G. ncRNA-regulated immune response and its role in inflammatory lung diseases. Am J Physiol Lung Cell Mol Physiol. 2015;309(10):L1076-87. http://dx.doi.org/10.1152/ajplung. 00286.2015 
44. Feng W, Su Z, Yin Q, Zong W, Shen X, Ju S. ncRNAs associated with drug resistance and the therapy of digestive system neoplasms. J Cell Physiol. 2019;234(11):19143-19157. http://dx.doi.org/10.1002/ jcp. 28551

45. Ayers D, Vandesompele J. Influence of microRNAs and long non-coding RNAs in cancer chemoresistance. Genes (Basel). 2017;8(3):pii:E95. http://dx.doi.org/10.3390/genes8030095

46. Shao F, Huang M, Meng F, Huang Q. Circular RNA signature predicts gemcitabine resistance of pancreatic ductal adenocarcinoma. Front Pharmacol. 2018;9:584. http://dx.doi.org/10.3389/fphar. 2018.00584

47. Vidigal JA, Ventura A. The biological functions of miRNAs: Lessons from in vivo studies. Trends Cell Biol. 2015;25(3):137-47. http://dx.doi.org/10.1016/j.tcb.2014.11.004

48. Hayes CN, Chayama K. MicroRNAs as biomarkers for liver disease and hepatocellular carcinoma. Int J Mol Sci. 2016;17(3):280. http://dx.doi.org/10.3390/ijms17030280

49. Tricoli L, Niture S, Chimeh U, Kumar D. Role of microRNAs in the development of hepatocellular carcinoma and acquired drug resistance. Front Biosci (Landmark Ed). 2019;24:545-54. http://dx.doi. org/10.2741/4734

50. Yahya S, Fathy SA, El-Khayat ZA, El-Toukhy SE, Hamed AR, Hegazy M, et al. Possible role of microRNA-122 in modulating multidrug resistance of hepatocellular carcinoma. Indian J Clin Biochem. 2018;33(1):21-30. http://dx.doi.org/10.1007/s12291-017-0651-8

51. Xu Y, Huang J, Ma L, Shan J, Shen J, Yang Z, et al. MicroRNA-122 confers sorafenib resistance to hepatocellular carcinoma cells by targeting IGF-1R to regulate RAS/RAF/ERK signaling pathways. Cancer Lett. 2016;371(2):171-81. http://dx.doi.org/10.1016/j.canlet.2015.11.034

52. He C, Dong X, Zhai B, Jiang X, Dong D, Li B, et al. MiR-2l mediates sorafenib resistance of hepatocellular carcinoma cells by inhibiting autophagy via the PTEN/Akt pathway. Oncotarget. 2015;6(30):28867-81. http://dx.doi.org/10.18632/oncotarget.4814

53. Zhuo L, Liu J, Wang B, Gao M, Huang A. Differential miRNA expression profiles in hepatocellular carcinoma cells and drug-resistant sublines. Oncol Rep. 2013;29(2):555-62. http://dx.doi.org/10.3892/ or.2012.2155

54. D'Arcy M. Cell death: A review of the major forms of apoptosis, necrosis and autophagy. Cell Biol Int. 2019;43(6):582-92. http://dx.doi.org/10.1002/cbin.11137

55. Kaczanowski S. Apoptosis: Its origin, history, maintenance and the medical implications for cancer and aging. Phys Biol. 2016;13(3):31001. http://dx.doi.org/10.1088/1478-3975/13/3/031001

56. Zhang B, Shan H, Li D, Li ZR, Zhu KS, Jiang ZB, et al. Cisplatin sensitizes human hepatocellular carcinoma cells, but not hepatocytes and mesenchymal stem cells, to TRAIL within a therapeutic window partially depending on the upregulation of DR5. Oncol Rep. 2011;25(2):461-68. http://dx.doi. org/10.3892/or.2010.1084

57. Feng F, Lu YY, Zhang F, Gao XD, Zhang CF, Meredith A, et al. Long interspersed nuclear element ORF-1 protein promotes proliferation and resistance to chemotherapy in hepatocellular carcinoma. World J Gastroenterol. 2013;19(7):1068-78. http://dx.doi.org/10.3748/wjg.v19.i7.1068

58. Zhou M, Zhang Q, Zhao J, Liao M, Wen S, Yang M. Phosphorylation of Bcl-2 plays an important role in glycochenodeoxycholate-induced survival and chemoresistance in HCC. Oncol Rep. 2017;38(3):1742-50. http://dx.doi.org/10.3892/or.2017.5830

59. Tutusaus A, Stefanovic M, Boix L, Cucarull B, Zamora A, Blasco L, et al. Antiapoptotic BCL-2 proteins determine sorafenib/regorafenib resistance and BH3-mimetic efficacy in hepatocellular carcinoma. Oncotarget. 2018;9(24):16701-17. http://dx.doi.org/10.18632/oncotarget.24673

60. Tredan O, Galmarini CM, Patel K, Tannock IF. Drug resistance and the solid tumor microenvironment. J Natl Cancer Inst. 2007;99(19):1441-54. http://dx.doi.org/10.1093/jnci/djm135

61. Liu K, Zhang X, Xu W, Chen J, Yu J, Gamble JR, et al. Targeting the vasculature in hepatocellular carcinoma treatment: Starving versus normalizing blood supply. Clin Transl Gastroenterol. 2017;8(6):e98. http://dx.doi.org/10.1038/ctg.2017.28

62. Koyama S, Matsunaga S, Imanishi M, Maekawa Y, Kitano H, Takeuchi H, et al. Tumour blood vessel normalisation by prolyl hydroxylase inhibitor repaired sensitivity to chemotherapy in a tumour mouse model. Sci Rep. 2017;7:45621. http://dx.doi.org/10.1038/srep45621 
63. Al TW, Dale TP, Al-Jumaily R, Forsyth NR. Hypoxia-modified cancer cell metabolism. Front Cell Dev Biol. 2019;7:4. http://dx.doi.org/10.3389/fcell.2019.00004

64. Rawat D, Chhonker SK, Naik RA, Mehrotra A, Trigun SK, Koiri RK. Lactate as a signaling molecule: Journey from dead end product of glycolysis to tumor survival. Front Biosci (Landmark Ed). 2019;24:366-81. http://dx.doi.org/10.2741/4723

65. Mendez-Blanco C, Fondevila F, Garcia-Palomo A, Gonzalez-Gallego J, Mauriz JL. Sorafenib resistance in hepatocarcinoma: Role of hypoxia-inducible factors. Exp Mol Med. 2018;50(10):134. http:// dx.doi.org/10.1038/s12276-018-0159-1

66. Vu NB, Nguyen TT, Tran LC, Do CD, Nguyen BH, Phan NK, et al. Doxorubicin and 5-fluorouracil resistant hepatic cancer cells demonstrate stem-like properties. Cytotechnology. 2013;65(4):491-503. http://dx.doi.org/10.1007/s10616-012-9511-9

67. Cox J, Weinman S. Mechanisms of doxorubicin resistance in hepatocellular carcinoma. Hepat Oncol. 2016;3(1):57-59. http://dx.doi.org/10.2217/hep.15.41

68. Oishi N, Yamashita T, Kaneko S. Molecular biology of liver cancer stem cells. Liver Cancer. 2014;3(2):71-84. http://dx.doi.org/10.1159/000343863

69. Yamashita T, Wang XW. Cancer stem cells in the development of liver cancer. J Clin Invest. 2013;123(5):1911-18. http://dx.doi.org/10.1172/JCI66024

70. Ji J, Wang XW. Clinical implications of cancer stem cell biology in hepatocellular carcinoma. Semin Oncol. 2012;39(4):461-72. http://dx.doi.org/10.1053/j.seminoncol.2012.05.011

71. Ling S, Li J, Shan Q, Dai H, Lu D, Wen X, et al. USP22 mediates the multidrug resistance of hepatocellular carcinoma via the SIRT1/AKT/MRP1 signaling pathway. Mol Oncol. 2017;11(6):682-95. http:// dx.doi.org/10.1002/1878-0261.12067

72. Ma S, Lee TK, Zheng BJ, Chan KW, Guan XY. CD133+ HCC cancer stem cells confer chemoresistance by preferential expression of the Akt/PKB survival pathway. Oncogene. 2008;27(12):1749-58. http:// dx.doi.org/10.1038/sj.onc.1210811

73. Huang M, Chen C, Geng J, Han D, Wang T, Xie T, et al. Targeting KDMlA attenuates Wnt/betacatenin signaling pathway to eliminate sorafenib-resistant stem-like cells in hepatocellular carcinoma. Cancer Lett. 2017;398:12-21. http://dx.doi.org/10.1016/j.canlet.2017.03.038

74. Thorburn A. Autophagy and disease. J Biol Chem. 2018;293(15):5425-30. http://dx.doi.org/10.1074/ jbc.R117.810739

75. Li YJ, Lei YH, Yao N, Wang CR, Hu N, Ye WC, et al. Autophagy and multidrug resistance in cancer. Chin J Cancer. 2017;36(1):52. http://dx.doi.org/10.1186/s40880-017-0219-2

76. Huang F, Wang BR, Wang YG. Role of autophagy in tumorigenesis, metastasis, targeted therapy and drug resistance of hepatocellular carcinoma. World J Gastroenterol. 2018;24(41):4643-51. http:// dx.doi.org/10.3748/wjg.v24.i41.4643

77. Sheng J, Qin H, Zhang K, Li B, Zhang X. Targeting autophagy in chemotherapy-resistant of hepatocellular carcinoma. Am J Cancer Res. 2018;8(3):354-65.

78. Fan T, Zhang C, Zong M, Zhao Q, Yang X, Hao C, et al. Peptidylarginine deiminase IV promotes the development of chemoresistance through inducing autophagy in hepatocellular carcinoma. Cell Biosci. 2014;4:49. http://dx.doi.org/10.1186/2045-3701-4-49 [Epub ahead of print].

79. Wiese M, Stefan SM. The A-B-C of small-molecule ABC transport protein modulators: From inhibition to activation-a case study of multidrug resistance-associated protein 1 ( $\mathrm{ABCCl}$ ). Med Res Rev. 2019. http://dx.doi.org/10.1002/med.21573

80. Kaushik V, Yakisich JS, Kumar A, Azad N, lyer A. Ionophores: Potential use as anticancer drugs and chemosensitizers. Cancers (Basel). 2018;10(10):E360. http://dx.doi.org/10.3390/cancers10100360

81. Tammam SN. Lipid based nanoparticles as inherent reversing agents of multidrug resistance in cancer. Curr Pharm Des. 2017. http://dx.doi.org/10.2174/1381612823666171122104738 [Epub ahead of print].

82. Limeres MJ, Moretton MA, Bernabeu E, Chiappetta DA, Cuestas ML. Thinking small, doing big: Current success and future trends in drug delivery systems for improving cancer therapy with special focus on liver cancer. Mater Sci Eng C Mater Biol Appl. 2019;95:328-41. http://dx.doi.org/10.1016/j. msec.2018.11.001

83. Larsson M, Huang WT, Liu DM, Losic D. Local co-administration of gene-silencing RNA and drugs in cancer therapy: State-of-the art and therapeutic potential. Cancer Treat Rev. 2017;55:128-35. http:// dx.doi.org/10.1016/j.ctrv.2017.03.004 
84. Guo Q, Cao H, Qi X, Li H, Ye P, Wang Z, et al. Research progress in reversal of tumor multi-drug resistance via natural products. Anticancer Agents Med Chem. 2017;17(11):1466-76. http://dx.doi. org/10.2174/1871520617666171016105704

85. Kim JH, Chung JB, Park IS, Kim BS, Yoo NC, Choi JH, et al. Combined use of tamoxifen, cyclosporin A, and verapamil for modulating multidrug resistance in human hepatocellular carcinoma cell lines. Yonsei Med J. 1993;34(1):35-44. http://dx.doi.org/10.3349/ymj.1993.34.1.35

86. Thomas H, Coley HM. Overcoming multidrug resistance in cancer: An update on the clinical strategy of inhibiting p-glycoprotein. Cancer Contr. 2003;10(2):159-65. http://dx.doi. org/10.1177/107327480301000207

87. Koski A, Raki M, Nokisalmi P, Liikanen I, Kangasniemi L, Joensuu T, et al. Verapamil results in increased blood levels of oncolytic adenovirus in treatment of patients with advanced cancer. Mol Ther. 2012;20(1):221-9. http://dx.doi.org/10.1038/mt.2011.230

88. Warmann S, Gohring G, Teichmann B, Geerlings H, Pietsch T, Fuchs J. P-glycoprotein modulation improves in vitro chemosensitivity in malignant pediatric liver tumors. Anticancer Res. 2003;23(6C):4607-11.

89. Gottesman MM, Ludwig J, Xia D, Szakacs G. Defeating drug resistance in cancer. Discov Med. 2006;6(31):18-23.

90. Kakarla P, Inupakutika M, Devireddy AR, Gunda SK, Willmon TM, Ranjana KC, et al. 3D-QSAR and contour map analysis of tariquidar analogues as multidrug resistance protein-l (MRP1) inhibitors. Int J Pharm Sci Res. 2016;7(2):554-72.

91. Nobili S, Landini I, Mazzei T, Mini E. Overcoming tumor multidrug resistance using drugs able to evade P-glycoprotein or to exploit its expression. Med Res Rev. 2012;32(6):1220-62. http://dx.doi. org/10.1002/med.20239

92. Takahata T, Ookawa K, Suto K, Tanaka M, Yano H, Nakashima O, et al. Chemosensitivity determinants of irinotecan hydrochloride in hepatocellular carcinoma cell lines. Basic Clin Pharmacol Toxicol. 2008;102(4):399-407. http://dx.doi.org/10.1111/j.1742-7843.2007.00199.x

93. Aslan B, Ozpolat B, Sood AK, Lopez-Berestein G. Nanotechnology in cancer therapy. J Drug Target. 2013;21(10):904-13. http://dx.doi.org/10.3109/1061186X.2013.837469

94. Alakhova DY, Rapoport NY, Batrakova EV, Timoshin AA, Li S, Nicholls D, et al. Differential metabolic responses to pluronic in MDR and non-MDR cells: A novel pathway for chemosensitization of drug resistant cancers. J Control Release. 2010;142(1):89-100. http://dx.doi.org/10.1016/j.jconrel.2009.09.026

95. Wang SB, Ma YY, Chen XY, Zhao YY, Mou XZ. Ceramide-graphene oxide nanoparticles enhance cytotoxicity and decrease HCC xenograft development: A novel approach for targeted cancer therapy. Front Pharmacol. 2019;10:69. http://dx.doi.org/10.3389/fphar.2019.00069

96. Wang W, Huang S, Yuan J, Xu X, Li H, Lv Z, et al. Reverse multidrug resistance in human HepG2/ ADR by anti-miR-21 combined with hyperthermia mediated by functionalized gold nanocages. Mol Pharm. 2018;15(9):3767-76. http://dx.doi.org/10.1021/acs.molpharmaceut.8b00046

97. Yang T, Chen Y, Zhao P, Xue H, You J, Li B, et al. Enhancing the therapeutic effect via elimination of hepatocellular carcinoma stem cells using Bmil siRNA delivered by cationic cisplatin nanocapsules. Nanomedicine-UK. 2018;14(7):2009-21. http://dx.doi.org/10.1016/j.nano.2018.05.012

98. Bobbin ML, RossiJJ. RNA Interference (RNAi)-based therapeutics: Delivering on the pPromise? Annu Rev Pharmacol Toxicol. 2016;56:103-22. http://dx.doi.org/10.1146/annurev-pharmtox-010715-103633

99. Hosseinahli N, Aghapour M, Duijf P, Baradaran B. Treating cancer with microRNA replacement therapy: A literature review. J Cell Physiol. 2018;233(8):5574-88. http://dx.doi.org/10.1002/jcp.26514

100. Hajiasgharzadeh K, Somi MH, Shanehbandi D, Mokhtarzadeh A, Baradaran B. Small interfering RNAmediated gene suppression as a therapeutic intervention in hepatocellular carcinoma. J Cell Physiol. 2019;234(4):3263-76. http://dx.doi.org/10.1002/jcp.27015

101. Mansoori B, Sandoghchian SS, Baradaran B. RNA interference and its role in cancer therapy. Adv Pharm Bull. 2014;4(4):313-21.

102. Lambeth LS, Smith CA. Short hairpin RNA-mediated gene silencing. Methods Mol Biol. 2013;942: 205-32. http://dx.doi.org/10.1007/978-1-62703-119-6_12

103. Chen X, Mangala LS, Rodriguez-Aguayo C, Kong X, Lopez-Berestein G, Sood AK. RNA interferencebased therapy and its delivery systems. Cancer Metastasis Rev. 2018;37(1):107-24. http://dx.doi. org/10.1007/s10555-017-9717-6 
104. Esmailzadeh S, Mansoori B, Mohammadi A, Shanehbandi D, Baradaran B. siRNA-Mediated silencing of HMGA2 induces apoptosis and cell cycle arrest in human colorectal carcinoma. J Gastrointest Cancer. 2017;48(2):156-63. http://dx.doi.org/10.1007/s12029-016-9871-z

105. Tang B, Zhang Y, Liang R, Gao Z, Sun D, Wang L. RNAi-mediated EZH2 depletion decreases MDRI expression and sensitizes multidrug-resistant hepatocellular carcinoma cells to chemotherapy. Oncol Rep. 2013;29(3):1037-42. http://dx.doi.org/10.3892/or.2013.2222

106. Rudalska R, Dauch D, Longerich T, McJunkin K, Wuestefeld T, Kang TW, et al. In vivo RNAi screening identifies a mechanism of sorafenib resistance in liver cancer. Nat Med. 2014;20(10):1138-46. http:// dx.doi.org/10.1038/nm.3679

107. Peng W, DU T, Zhang Z, DU F, Jin J, Gong A. Knockdown of autophagy-related gene LC3 enhances the sensitivity of HepG2 cells to epirubicin. Exp Ther Med. 2015;9(4):1271-76. http://dx.doi. org/10.3892/etm.2015.2266

108. Tang S, Tan G, Jiang X, Han P, Zhai B, Dong X, et al. An artificial lncRNA targeting multiple miRNAs overcomes sorafenib resistance in hepatocellular carcinoma cells. Oncotarget. 2016;7(45):73257-69. http://dx.doi.org/10.18632/oncotarget.12304

109. Li GM, Wang YG, Pan Q, Wang J, Fan JG, Sun C. RNAi screening with shRNAs against histone methylation-related genes reveals determinants of sorafenib sensitivity in hepatocellular carcinoma cells. Int J Clin Exp Pathol. 2014;7(3):1085-92.

110. Lou JS, Yao P, Tsim K. Cancer treatment by using traditional Chinese medicine: Probing active compounds in anti-multidrug resistance during drug therapy. Curr Med Chem. 2018;25(38):5128-41. http://dx.doi.org/10.2174/0929867324666170920161922

111. Wang H, Zhai Z, Li N, Jin H, Chen J, Yuan S, et al. Steroidal saponin of Trillium tschonoskii. Reverses multidrug resistance of hepatocellular carcinoma. Phytomedicine. 2013;20(11):985-91. http://dx. doi.org/10.1016/j.phymed.2013.04.014

112. Jia H, Yang Q, Wang T, Cao Y, Jiang QY, Ma HD, et al. Rhamnetin induces sensitization of hepatocellular carcinoma cells to a small molecular kinase inhibitor or chemotherapeutic agents. Biochim Biophys Acta. 2016;1860(7):1417-30. http://dx.doi.org/10.1016/j.bbagen.2016.04.007 